\title{
Preventive Oral Health Care in a School for Children with Special Health Care Needs
}

\author{
Kittichai Sireerat ${ }^{1}$, Patcharaphol Samnieng ${ }^{2 *}$ \\ ${ }^{1}$ Faculty of dentistry, Naresuan University, Thailand \\ ${ }^{2}$ Department of Preventive Dentistry, Faculty of dentistry, Naresuan University, Thailand \\ *Email: patcharaphols@yahoo.com
}

\begin{abstract}
Purpose: The objectives of this study were 1. To examine the oral health status of children with special health care needs and 2 . To evaluate a preventive oral health care program for these children. Method: Subjects included 32 children in a special health care needs school who were given an oral examination. The DMFT/dmft and DI-S indices were used to assess their oral health status. A preventive oral health care program was developed by focus group discussion (teachers, parents, caregivers, and dental students). The children's oral health status was evaluated 1 year after the initiation of a preventive oral health program. Result: In the year 2015, the average DMFT and dmft scores were 3.2 and 2.23, respectively, and DI-S score was 2.15. The preventive oral health care program consisted of the following: 1. A policy for fruit or non-sugar or low-sugar between-meal snacks; 2. Instruction for the children to brush their teeth after meals; and 3. Routine fluoride mouth rinsing after snack time. After the preventive oral health program, the average DMFT and dmft scores in the year 2016 were 1.4 and 1.6, respectively, and the average DI-S score was 2.1. Conclusion: The oral health status of children with special health care needs was poor. A preventive oral health care program was effective at improving the oral health of children with special needs. Participation of all stakeholders was important.
\end{abstract}

Keywords: children with special needs; preventive oral health care

\section{Introduction}

Children with special health care needs (CSHCN) are those "who have or are at increased risk for a chronic physical, developmental, behavioral, or emotional condition and who require health and related services of a type or amount beyond that required by children generally." [1] Children with mental retardation, autism, and Down syndrome are included in CSHCN.

In the case of children with mental retardation, they have problems with learning, behavior, and adaptation in society. It is necessary to assess their severity of mental retardation for the purpose of communication by asking the caregivers about their ability to learn, communicate, and self-care. Using repeated conversation and simple words are ways to communicate with them. In contrast, children with Down syndrome, most of who are not of low intelligence, can cooperatively communicate if the information being communicated is not difficult to understand. Autistic children have not only behavior problems but also social and language learning disabilities and difficulty understanding the meaning of a 
conversation. Therefore, these CSHCNs may be at an increased risk of oral diseases throughout their lives. Oral diseases can have a direct and devastating impact on the health and quality of life of those with certain systemic health problems or conditions. [2]

Dental caries, periodontal disease, and malocclusion are common among CSHCN. Many studies reported that individuals with special health care needs have poorer oral $[3,4,5] \mathrm{CSHCN}$ are less capable of taking care of themselves and are often missed by oral health campaigns. [6] Oral health care for CSHCN can be delivered in three dimensions: nutrition, oral hygiene maintenance, and the accessibility of dental services. The solution to better care for CSHCN is to involve the children and their families and caregivers. [7] The key to improving access to oral health care for CSHCN is understanding that having medical and dental care at home are vital to overall health and sustained quality life. [8]

In Thailand, there is only a small amount of data about oral health status and preventive oral health care programs for CSHCN. The following were the objectives of this study: 1. To examine the oral health status of CSHCN and 2. To evaluate a preventive oral health care program for CSHCN.

\section{Materials and Methods}

\subsection{Subjects}

Thirty-two CSHCN ( 25 boys and 7 girls, mean age: $8.81 \pm 3.35$ years) who attended the school for CSHCN in the Department of Special Education, Pibulsongkram Rajabhat University in Phitsanulok province, Thailand were included in the study.

This study was approved by the ethics committee of the faculty of dentistry, Naresuan University, and informed consent was obtained from both teachers and caregivers of the participants.

\subsection{Oral Examinations}

Before performing the dental examination, we carried out an assessment of each child and learned how to manage their behaviors. We obtained information from the teachers on the children's medical conditions, allergies, and habits and prepared a management plan appropriate for their conditions. Examination charts were designed for the children, and consent forms were sent to the parents and caregivers. We then consulted the teachers and prepared the location for taking the dental examination.

The DMFT/dmft and DI-S indices were used to assess the children's oral health. The DMFT is the Decayed, Missing, and Filled Teeth Index, which is the universally employed index for measuring the dental caries status of permanent teeth. The DMFT index quantifies dental caries status in terms of $\mathrm{D}$, the number of decayed teeth with untreated caries lesions; $\mathrm{M}$, the number of teeth that have been lost due to caries; and F, the number of filled teeth presented. [9] The dmft index was used to assess primary teeth. [10]

Oral hygiene was assessed using the debris index simplified (DI-S) score. The DI-S score describes the extent of soft debris deposits and is one of the two components of the simplified oral hygiene index (OHI-S). The simplified DI-S evaluates the labial surfaces of teeth $11,16,26$, and 31 and the lingual surfaces of teeth 36 
and 46. Each tooth surface is divided horizontally into gingival, middle, and incisal thirds. The DI-S is scored as 0: no debris or stain present, 1: soft debris covering not more than one-third of the tooth surface; 2 : soft debris covering more than onethird, but not more than two-third of the exposed surface; and 3: soft debris covering more than two-thirds of the exposed surface. The DI-S score is the sum of the debris scores for all teeth divided by the number of surfaces scored. To give clinical relevance to the index, oral cleanliness was defined as "good" if the DI-S score was between 0.3 and 0.6 , "fair" between 0.7 and 1.8, and "poor" between 1.9 and 3.0 [11].

\subsection{Focus Group Discussion}

The objectives of the focus group were to inform the teachers, parents, and caregivers of the children's oral health to raise their awareness of the children's oral health problems. These three groups would participate in finding alternatives for preventing oral health problems in the children. The procedure was as follows: we informed the focus group of the objectives and reported the children's oral health information to the parents and caregivers. We then gave them oral hygiene instructions for the CSHCN. The teachers' opinions, alternatives, and limitations for preventive oral health care for $\mathrm{CSHCN}$ from the previous focus group were also reported to the parents and caregivers. After that, a conversation on the topic "Preventive oral health care for CSHCN" was taken with parents, caregivers, and teachers together. We divided the parents and caregivers, along with the respective teachers, into groups by classroom. Each group held discussions and found alternatives for preventing their children's oral health problems. Finally, each group presented and shared their solutions with the rest of the groups.

\subsection{Follow-up}

Preventive oral health care in the school for CSHCN was evaluated at the 1-year follow-up. The evaluation was carried out by oral exam and by asking about the parents/caregiver's satisfaction with the program.

\section{Results}

The study included 35 children, of whom 6 had Down's syndrome, 27 were autistic, 1 had cerebral palsy, and 1 was mentally retarded. The classrooms were divided into two sectors: kindergarten and primary education. There were four levels classified by the children's development in the kindergarten section (levels $1,2,3$, and 4). When the children had developed their life skills, they would move to the next level of the kindergarten classroom. The primary education section was divided into two levels.

There were 11 teachers in this school. The main role of teachers in this school was to develop the children's life skills. They were able to communicate with the children and manage their behaviors. In the role of health care, teachers would prepare the break-time snack and the lunch for the children. The children had to brush their teeth after the meal. If they could not brush their own teeth adequately, the teachers would brush for them. The children would then take an afternoon nap. The 
children were given a bath by the teacher after they had slept. In this way, the teachers were essential to the children's health when they were at school.

\subsection{Oral Examination Result}

The oral health of the CSHCN in this school was described using the DMFT/dmft and DI-S. In the year 2015, the average DMFT and dmft of this school were determined as 3.2 and 2.23, respectively. The DI-S score in year 2015 was 2.15 , which could be described as poor oral hygiene. Children with Down syndrome tended to have a higher number of caries and poorer oral hygiene than other children.

\subsection{Focus Group Discussion Result}

A preventive oral health care plan resulted from the focus group discussion. The program included three activities: 1. Policy for fruit or non-sugar or low-sugar between-meal snacks. 2. Instructing the children to brush their teeth after meals, and 3. Routine fluoride mouth rinsing after snack time. The teachers, parents, or caregivers received oral hygiene education from dental students, including toothbrush selection, tooth brushing, dental flossing, and oral disease prevention. The teachers, parents, and caregivers would brush the teeth of children who were not able to brush their own teeth. The fluoride mouth rinse $(0.2 \%$ sodium fluoride) was prepared by the Faculty of Dentistry, Naresuan University.

\subsection{Evaluation}

A comparison of the oral health status of CSHCN before and after 1 year of the program is shown in Table 1. We found no incidents of dental caries in this school. The DI-S score was not significantly different.

\section{Discussion}

The oral health status of CSHCN in this study was poor. A high DMFT score (2.23 teeth per child) and a high score for oral hygiene assessment (2.15) were obtained. Our results were consistent with those of a study on the oral health status and treatment needs of CSHCN conducted in Khon Kaen (northeastern Thailand), which showed an average dmft score of 1.9 teeth per child [6].

The oral health conditions of CSHCN may be influenced by age, severity of impairment, and living conditions. Individuals with special needs may have great limitations in oral hygiene performance due to their potential motor, sensory, and intellectual disabilities $[12,13,14]$ and thus, are prone to poor oral health. Individuals in these groups may not understand and assume responsibility for or cooperate with preventive oral health practices. [15] Children who are very young, those with severe impairments, and those living in institutions are dependent on parents, siblings, or caregivers for general care, including oral hygiene. Many caregivers do not have the requisite knowledge or values to recognize the importance of oral hygiene and do not themselves practice appropriate oral hygiene or choose a proper diet [16]. They may be more susceptible to dental caries if they reside at home and are pampered with cariogenic snacks and other unhealthy eating habits. Poor oral health conditions have also been linked to low socio-economic status. Poor and nearly poor CSHCNs and those with greater limitations attributable to their disability are more 
likely to have unmet dental care needs [17]. The current study data support the need for all caregivers and dental professional to be concerned about the oral health of CSHCN.

Various factors create barriers to receiving oral health care even among the elite; these include low priority placed on oral health by parents and chronicity of oral diseases. If oral health is not perceived as being important, the children will not be taken for dental check-ups [18]. A family's inability to be committed to children's dental care may also result from a lack of understanding of the long-term health risks that may burden a child who does not receive urgently needed care [19]. A preventive oral health care program for CSHCN is urgently needed.

Some of the reasons for the increased occurrence of dental caries in CSHCN are increased thirst, eating for consolation or comfort, consumption of sweets and sweet drinks, [20] and long-term consumption of medications in the form of sweetened syrups. High sugar consumption is an important cause of dental caries in CSHCN and all children [21]. Since the policy of providing lower sugar between-meal snacks was implemented, the incidence of dental caries decreased. It is difficult to change the snacking behaviors of children; therefore, the participation of teachers and caregivers is of paramount importance.

Although the children had been taught to clean their mouths, their DI-S scores were still assessed as poor. This showed that they were not capable of caring for their own oral health due to their conditions or limitations. The results of this study agree with those of a study conducted in India on the "Oral Hygiene Needs of Special Children and the Effects of Supervised Tooth Brushing," which showed that the CSHCN group still had poor oral hygiene, even after receiving education, which may be attributed to their lack of coordination, lack of understanding, physical disability, or limited muscle strength [22].

This study showed that teachers and caregivers were satisfied with the effectiveness of a fluoride mouth rinse for CSHCN. Levin et al. reported that rinsing with fluoride was effective in lowering DMFT levels in socioeconomically depressed areas $[23,24]$. According to a review regarding fluoride mouth rinses, they are often empirically recommended for CSHCNs [25]. A school-based fluoride mouth rinsing program is also recommended in fluoride-deficient communities [26].

This oral preventive program may not be successful unless the efforts of teachers, parents, and caregivers are coordinated. After receiving education on oral health prevention, they can educate their children to have good oral health. In addition, family caregivers provide vital care management, transportation services, social support, socialization, and services for their children that have great impact on their overall health and quality of life [27]. Research conducted in Thailand about the oral care of intellectually disabled students indicated that the reason for students' improper oral health care was a lack of cooperation between the students and their parents and other family members, and the risk of oral disease was a going concern [7]. Thus, caregiver cooperation is of great importance to an oral preventive program.

Although this preventive program tends to be successful in oral prevention in schools, CSHCN have many conditions of which teachers and caregivers must be 
aware. $\mathrm{CSHCN}$ are at a greater risk of oral disease than ordinary children. Therefore, this oral preventive program requires further improvement. Once applied to these children's oral health, it can also be a model for other schools.

This study was limited by the small number of subjects who participated in the screening. Students who did not return their consent forms, were not in school on the days of screening, became sick, or were uncooperative were excluded from participating. All these factors are common in such institutions. However, enrolment in such institutions is increasing, and more institutions are being established; therefore, larger populations are expected in future studies.

\section{Conclusion}

The oral health status of CSHCN is poor. A preventive oral care program was effective at improving the oral health of CSHCN. Participation of all stakeholders is important.

\section{References}

1 McPherson M, Arango P, Fox H, Lauver C, McManus M, Newacheck PW, Perrin JM, Shonkoff JP, Strickland B. A new definition of children with special health care needs. Pediatr. 1998;102(1):137-9.

2 American Academy of Pediatric Dentistry. Guideline on management of dental patients with special health care needs. Pediatr Dent. 2012;34(5):160.

3 Tesini DA. An annotated review of the literature of dental caries and periodontal disease in mentally retarded individuals. Spec Care Dentist. 1981;1(2):75-87.

4 Nunn JH, Gordon PH, Carmichael CL. Dental Disease and current treatment needs in a group of physically handicapped children. Community Dent Health. 1993;10(4):38996.

5 Martens L, Marks L, Goffin G, Gizani S, Vinckier F, Declerck D. Oral hygiene in 12 year - old disabled children in Flanders, Belgium, related to manual dexterity. Community Dent Oral Epidemiol. 2000;28(1):73-80.

6 Weraarchakul W, Weraarchakul W, Angwarawong O. Oral health status and treatment need of disabled children in rehabilitation school in Khon Kaen, Thailand. ศรีนครินทร์ เวช สาร (Srinagarind Med J). 2005;20(1):17-23.

7 Thongkamkul P. Oral health care of the intellectual disable students by parents, Kawila Anukul School Chiang mai. Chiang mai: Chiang mai university; 2013.

8 Thikkurissy S, Lal S. Oral health burden in children with systemic diseases. Dent Clin. 2009;53(2):351-7.

9 Mehta A. Comprehensive review of caries assessment systems developed over the last decade. RSBO Revista Sul-Brasileira de Odontologia. 2012;9(3): 316-321.

10 Azizi Z. The prevalence of dental caries in primary dentition in 4-to 5-year-old preschool children in northern Palestine. Int Journal Dent. 2014; 2014:1-5.

11 Al-Mutawa SA, Shyama M, Al-Duwairi Y, Soparkar P. Oral hygiene status of Kuwaiti schoolchildren/Etat d'hygiene bucco-dentaire des ecoliers koweitiens. East Mediterr Health J. 2011;17(5):387.

12 Nunn JH. The dental health of mentally and physically handicapped children: a review of the literature. Community Dent Health. 1986; 4:157-6.

13 Kamen S, Crespi P, Ferguson FS. Dental management of the physically handicapped patients. Special and Medically Compromised Patients in Dentistry. 1989 Mar 1:25-6. 
14 Dahle AJ, Wesson DM, Thornton JB. Dentistry and the patient with sensory impairment. Special and medically compromised patients in dentistry. Massachusetts: PSG Publishing; 1989. p.66-67.

15 Holt K, Barzel R, eds. 2017. Oral Health Services for Children and Adolescents with Special Health Care Needs: A Resource Guide. Washington, DC: National Maternal and Child Oral Health Resource Center. 2005. Available from: https://www.mchoralhealth.org/.

16 Bonito A. Executive summary: dental care considerations for vulnerable populations. Special care in dentistry: official publication of the American Association of Hospital Dentists, the Academy of Dentistry for the Handicapped, and the American Society for Geriatric Dentistry. 2002;22(3 Suppl):5S-10S.

17 Lewis C, Robertson AS, Phelps S. Unmet dental care needs among children with special health care needs: implications for the medical home. Pediatr. 2005;116(3):e426-31.

18 Nagahama SI, McNabb K, Vanderlinde M, Cobb K, Moore CS, Milgrom P, Coldwell SE. Improving utilization of preventive dental services by medicaid-enrolled children: focus on the parents. J Dent Child. 2002;69(3):325-31.

19 Roman KM. Strategic planning: the at-risk pediatric patient. Pediatr Dent Today. 2007; 43:48-9.

20 Ahlborg B. Practical prevention. In: Nunn JH. Disability and oral care. FDI World Dental Press; 2000: 29-39.

21 Touger-Decker R, Van Loveren C. Sugars and dental caries. Am J Clin Nutr. 2003 ;78(4):881S-92S.

22 Lamba R., Rajvanshi H., Sheikh Z., Khurana M., Saha R. Oral hygiene needs of special children and the effective of supervised tooth brushing. Int J Sci Study 2015;3 Suppl 5: 30-35.

23 Adair SM. Evidence-based use of fluoride in contemporary pediatric dental practice. Pediatr Dent. 2006;28(2):133-42.

24 Levin KA, Jones CM, Wight C, Valentine C, VA Topping G, Naysmith R. Fluoride rinsing and dental health inequalities in 11 - year - old children: an evaluation of a supervised school - based fluoride rinsing programme in Edinburgh. Community Dent Oral Epidemiol. 2009;37(1):19-26.

25 Wei SHY, Yiu CKY. Mouthrinses: recent clinical finding and implications for use. Int Dent J 1993;43: 541-547.

26 ASTDD. School-base fluoride mouthrinse programs policy statement. Association of State \& Territorial Dental Directors, Nevada. March 1, 2011. https://www.astdd.org/docs/school-based-fluoride-mouthrinse-programs-policy-statement-march-1-2011.pdf.

27 Romley JA, Shah AK, Chung PJ, Elliott MN, Vestal KD, Schuster MA. Family-provided health care for children with special health care needs. Pediatr. 2017;139(1):e20161287. 